\title{
Landscape as Urban Regeneration: Learning from The High Line \& Seoullo 7017 Skypark
}

\author{
Romi Bramantyo Margono ${ }^{1}$, Siswanti Zuraida ${ }^{2}$ \\ Human Settlement Program, Faculty of Science Engineering , Katholieke Universite Leuven, Leuveun, Belgium \\ Civil Engineering Department, Faculty of Engineering and Design, Institut Teknologi Sains Bandung, Bekasi, \\ Indonesia \\ E-mail: bramantyomargono@gmail.com \\ siswanti.zuraida@gmail.com
}

Informasi naskah:

Diterima

31 Mei 2019

Direvisi

31 Juli 2019

Disetujui terbit

04 Agustus 2019

Diterbitkan

07 Agustus 2019

\begin{abstract}
Abstrak
Industrial Revolution has a significant contribution to forming the global cities. Many developments happened dictated by Industrial needs simultaneously with increasing number of populations by urbanization. One part of development to support industrialization and urbanization is infrastructures. Infrastructures such as street for cars and train railway. The development of infrastructures is affecting health, social, economic, and environment of citizen. It is also responsible for the decline of quality of life in many global cities. As time goes by, another significant shift happens in many global cities. Infrastructure becomes outdated, industry leaves, the local economy deflates, residents flee and the community implodes. It leaves many derelict infrastructures, other facilities of industry, and diverse impacts. To tackle this situation, Urban Regeneration concept was introduced. Furthermore, landscape also can be used as a tool of urban regeneration concept that intended to improve quality of life in the cities. According to this situation, there are two projects that represent landscape project as urban regeneration. The first project is The Highline project in New York by James Corner Field Operations, Diller Scofidio + Renfro, and Piet Oudolf that revitalizing previous railway and Seoullo 7017 Skygarden in South Korea by MVRDV that revitalizing previous highway. The aim of this paper are to presents more insight and elaboration about how urban regeneration implemented in the cities from two landscape projects example and describe some critical review of both projects.
\end{abstract}

Key words: landscape, urban regeneration, The High Line, Seoullo 7017 Skypark 


\section{INTRODUCTION}

Revolution of Industry is one of historical moment in human history that happened in the eighteenth and nineteenth centuries. The progress and development of industrialization affecting form of cities and towns in many places. It is also affecting the quality of life the people who live in towns and cities. It is affecting many aspects of human life for instance, social, economic, and environment. Indeed, the rapid urban transformation rooted in industrial drivers had forced several economic, social, physical and environmental changes on new societies so that Jonathan Rees describes this period of time as "The Shock of the new" for urbanization process ${ }^{1)}$.

Industrialization promoted crucial changes in the landscape: greater densities in urban areas and the urbanization of the natural and rural environment ${ }^{2)}$. One of the crucial changes that happened is the growth of infrastructure. It is driven by the needs of new workers that came to the city and massive population grow at that time. It has several positive effects such as that better quantity and quality of infrastructure can directly raise the productivity of human and physical capital and hence growth (e.g. by providing access, roads can: (i) improve education and markets for farmers' outputs and others by cutting costs, (ii) facilitate private investment, (iii) improve jobs and income levels for many) (Estache, 2012). But it also has negative effects, such as health problems, ecological destruction, climate change, and $\mathrm{CO} 2$ emissions ${ }^{3)}$.

After industrial era, another significant shift happens in many global cities. Infrastructure becomes outdated, industry leaves, the local economy deflates, residents flee and the community implodes ${ }^{4)}$. It leaves many derelict infrastructures, other facilities of industry, and diverse impacts. To tackle this situation, many efforts involving urban planners, developers, and leaders from global cities to rethink the future of the large number of industrial leftovers.

In order to deal with the issue, the abandoned infrastructure needs to be improved. It needs to adapt to new urban context and challenges. The concept of "Urban Regeneration" has been discussed to resolve problems caused by industrialization and urbanization ${ }^{5}$. Along with that landscape also can be part of Urban Regeneration scheme in cities.

To have more insight and elaboration about how urban regeneration implemented in the cities from landscape perspective, this paper will take two examples of projects. The first project is The High Line in New York by James Corner Field Operations, Diller Scofidio + Renfro, and Piet Oudolf and Seoullo 7017 Skygarden in South Korea by MVRDV. Moreover, this paper also presents critical comparison of both projects.

\section{THE HIGH LINE, NEW YORK, USA}

The Highline is one of the quintessential project that using landscape urbanism principles and ideas about sustainable design. It is considered successfully improve and give significant impact to the social, economy and environment surrounding area. The 
project story began when $9 \mathrm{~m}$ elevated railway train from meatpacking district declined in 1960. The decline happens because New York City changes from manufacturing to a postindustrial service economy ${ }^{6}$ and also caused by interstate trucking development. The railway completely stops working in 1980 .

As times goes by, the railway structure was abandoned and some part of the railway dismantled. Because of its condition, there was also plan to demolish all the railway, but Conrail as the owner of the railway did not want to demolish the remaining of the structure. It is actually due to the high cost that will be spent during demolition process. Conrail offered an alternative to use the structure as potential that still can be used for carrying freight in the future ${ }^{6)}$.

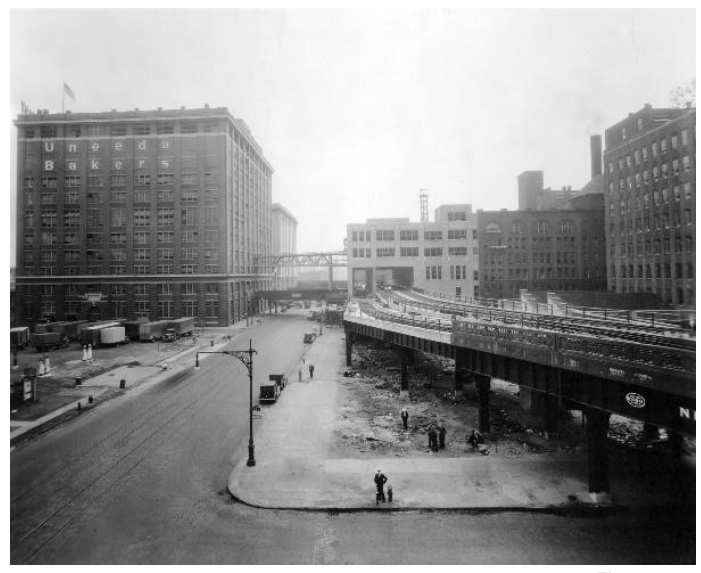

Figure 1. Early period of High Line ${ }^{7)}$

In 2004, a non-profit organization that called the Friends of High Line advocating to keep the railway. They held an international competition to collects idea for the existing high line. They selected the winner after receiving 720 ideas from over 36 countries. James Corner Field Operations and Diller Scofidio + Renfro is the winner of the competition and their proposal implemented to the remaining site. This project also involving Piet Oudolf landscape designer that giving a contribution to developing the landscape part of the site.

The existing elevated railway tracks turned into elevated park. The basic concept is inspired from the existing landscape that has many wild plants during the abandoned period. After completion of the design, the first section of High Line span from Gansevoort to West 20th Street open for public in 2009.

The second section from West 20th to West 30th street was open in 2011 and the third section, from West 30th to West 34th, was open in 2014.

\section{SEOULLO 7017 SKYGARDEN, SEOUL, SOUTH}

The project name is Seoullo 7017 Skygarden and '7017' has several meanings, one of the meaning is 1970 and 2017. 1970 is the year when the structure was built and 2017 is the completion year of the new revitalization project. Previously it was Seoul Station 
Overpass that built in 1970s in the middle of Seoul. After decades, structural evaluation conducted and the result was grade D. Based on Special act on Safety and Maintenance of Facilities, D grade considered as insufficient. Considering this situation Seoul municipality made first decision to dismantle the structure. But after considering the shortage of connectivity of surrounding areas the decision changed. Seoul municipality decided to convert the overpass into pedestrian path to connect surrounding areas in line with the aim of the city to become "human-oriented" walkable city ${ }^{8)}$.

In initiation phase, public opinion from citizens was collected. Along with that, structural improvement has also been done for safety factor. The improvement changes the grade from grade D which means "insufficient" to grade B which means "satisfactory". Afterward, an invited design competition was held. The fundamental purpose of the competition was to restore the urban memory and sovereignty of the citizens over the place through conservation ${ }^{9)}$. The competition invited only 7 architects and landscape architects from Korea and foreign country. The competition result is MVRDV won the competition.

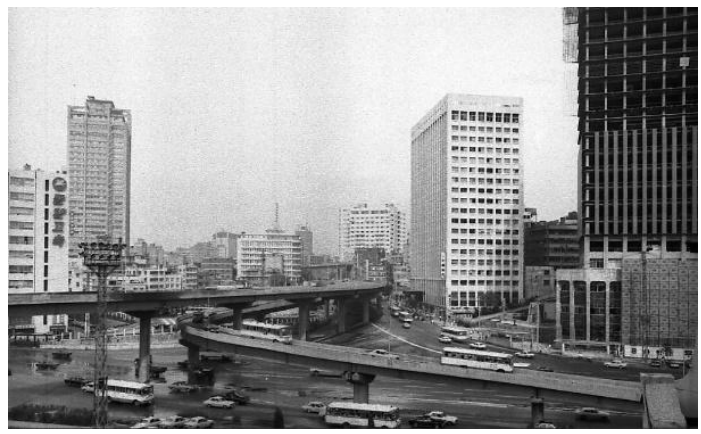

Figure 2. Early period of Seoul Station Overpass ${ }^{10)}$

The new proposal by MVRDV contains several main strategies. The first strategy is to add very diverse greenery on the top of the existing structure and create an arboretum. The second strategy is to connect the surrounding areas using 17 entrances that spread along the structure. The third strategy is to generate activities by providing spaces with various potential that is still open for future possibilities.

\section{DISCUSSION}

\subsection{Critical Review}

Both projects have similar basic context of abandoned infrastructure and using landscape intervention to improve the condition of the city. The concept of park as palimpsest embedded in both projects, it can be seen from the layers of design ${ }^{11)}$. In terms of design, each project has a different approach based on the surrounding context.

In High Line project the main idea is inspired by the wild seeded landscape that grows during abandoned period of High Line. The designer team try to recreate the image that will remind people of how it used to be. To create the image the designer team using several strategies. The first strategy is a paving system that enhances natural grow, creating 
"dissolving" path and fuzzy border. The pavement also offering various kind of gradation between pavement path to greeneries. It intended to imitate the richness of variation of nature path. The paving system also combined with the existing railway tracks those are visible to visitors. This strategy shows how interrelation between man-made construction "mingle" with nature.

Besides the gradation of pavement and plants, to make the concept of wild even bolder, the team also mixed various kind of plants of the indigenous plants to create a natural atmosphere. In addition, the various kind of plants also designed in various configuration, it goes from semi-open forest to meadow, to European meadow. By creating this variation of plants, spontaneously it will invite many animals, such as insects, squirrels, and birds. It is creating a new ecology and even become advocacy for ecology that rarely found in highly developing cities.

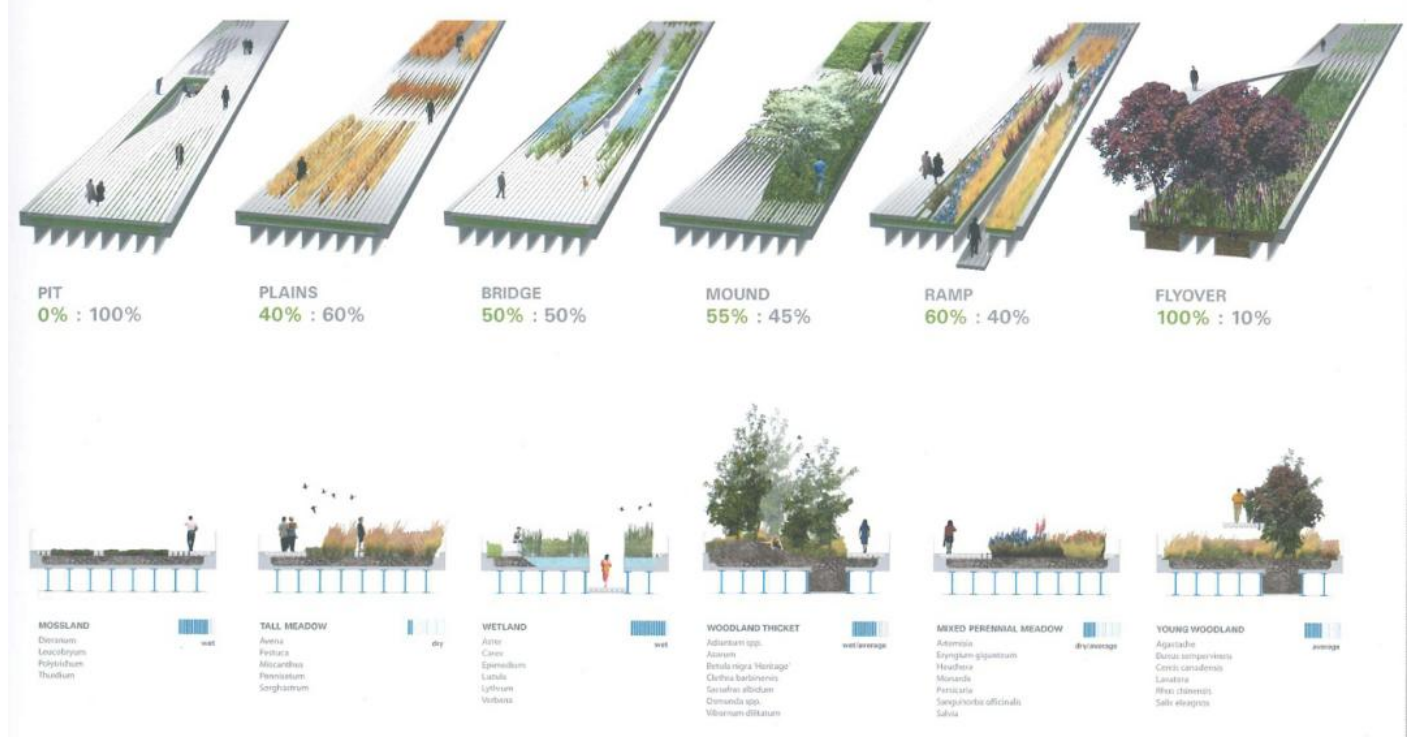

Figure 3. Various gradation between plants and paving area ${ }^{12)}$ 


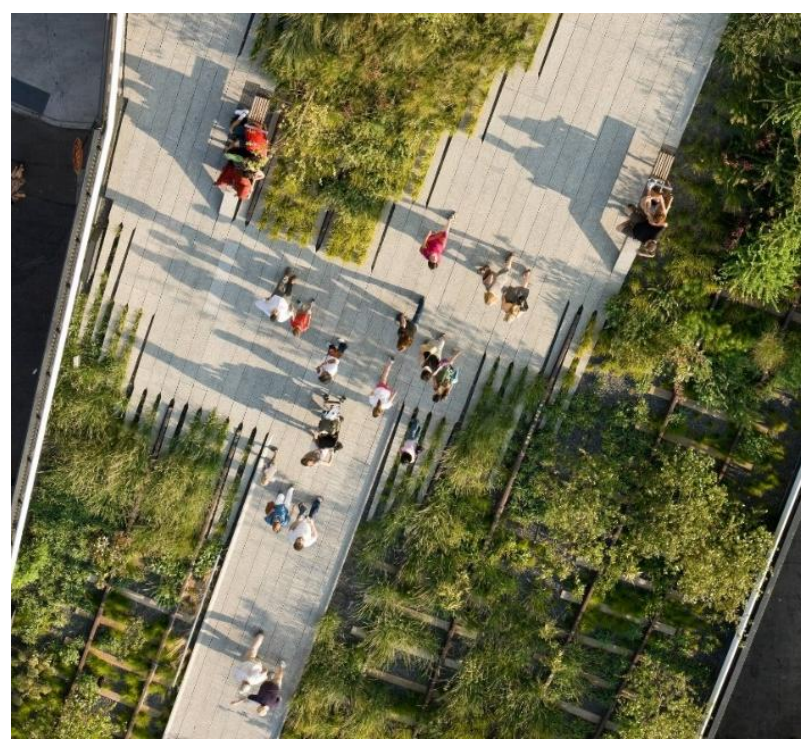

Figure 4. Dissolved Path ${ }^{13)}$

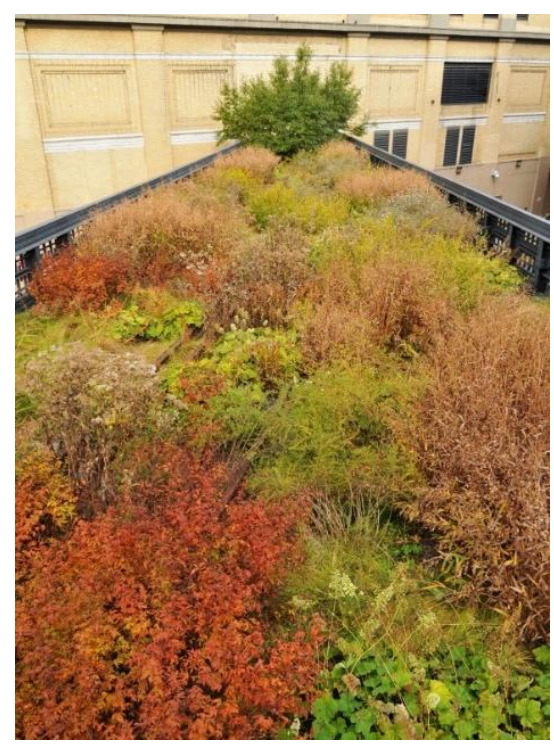

Figure 5. 'Wild" Plants ${ }^{14)}$

In Seoullo 7017 Skypark, MVRDV considered the strength of the existing structure limitation. Due to that limitation, the proposal strategy to add greenery on top of the structure is to use pots for plants. The concept of plantation that used in this project is library of plants. Instead of choosing specific plants, the project is gathering 50 families of plants including trees, shrubs, and flowers displayed in 645 tree pots, collecting around 228 species and sub-species. In total, the park will include 24,000 plants (trees, shrubs, and flowers) ${ }^{15)}$. The pots of plants arranged according to Korean alphabets (Hangeul). Visitors can see the information of plants that provided on the metal plate on pots. The project intended to be urban arboretum and testing ground to see how the plants grow in strictly urban situation. This intervention shows more about how strong human mastering the landscape by rigid boundary pots. It shows a controlled environment and much dominated by concrete.

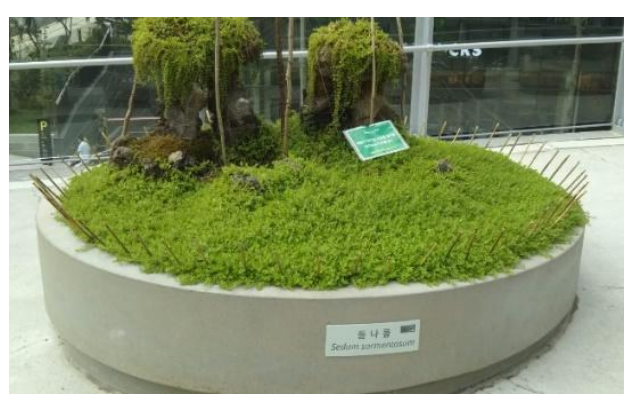

Figure 6. Pots with Information Plate ${ }^{15)}$

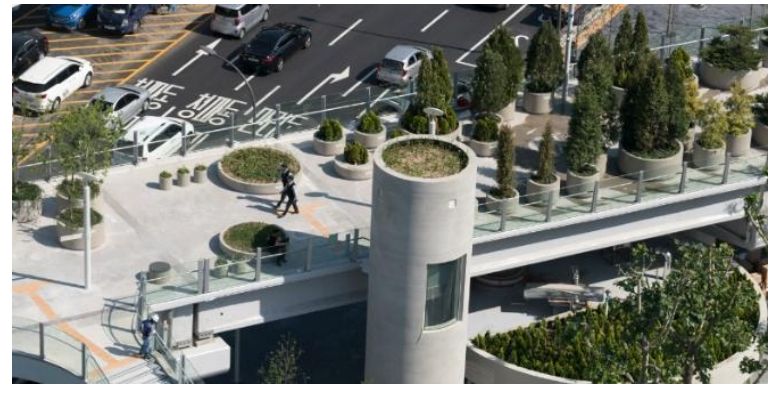

Figure 7. Pots of Plants in Seoullo 7017

Skypark ${ }^{16)}$ 
Long history of both structures has creating connection to the existing urban fabric. Their presence are not strange for surrounding area. The new intervention slightly changes the condition by adding more connection. For example, stairs, elevators, escalators and ramps added to increase the connection. Many surrounding buildings also want to connect with the structure and have direct access to the platforms. Economic speculation is the main motivation. It is not prohibited, but at some point, it can really change the project condition and damaging social and environment aspect. Keeping the balance between economy, environmental and social is the most important consideration to keep the project sustainable.

In political aspect, both projects have contribution from the mayor at that time. Both of project has supports from visionary mayor. It has a crucial role in the development of the projects. For example, in Highline, Previous mayor, Guilani, considered the project as an impediment to economic. Unlike Guilani. Mayor Bloomberg sees the project as an economic generator, this contrast point of view led to the policy that supports the project. In Seoullo, Mayor Park announced that the urban planning policy will be "different". He means instead of demolition and a preference for mega-structures, he argued for the regeneration of Seoul through reinventing old structures, thereby creating a modern reference to Seoul's identity and past ${ }^{15}$.

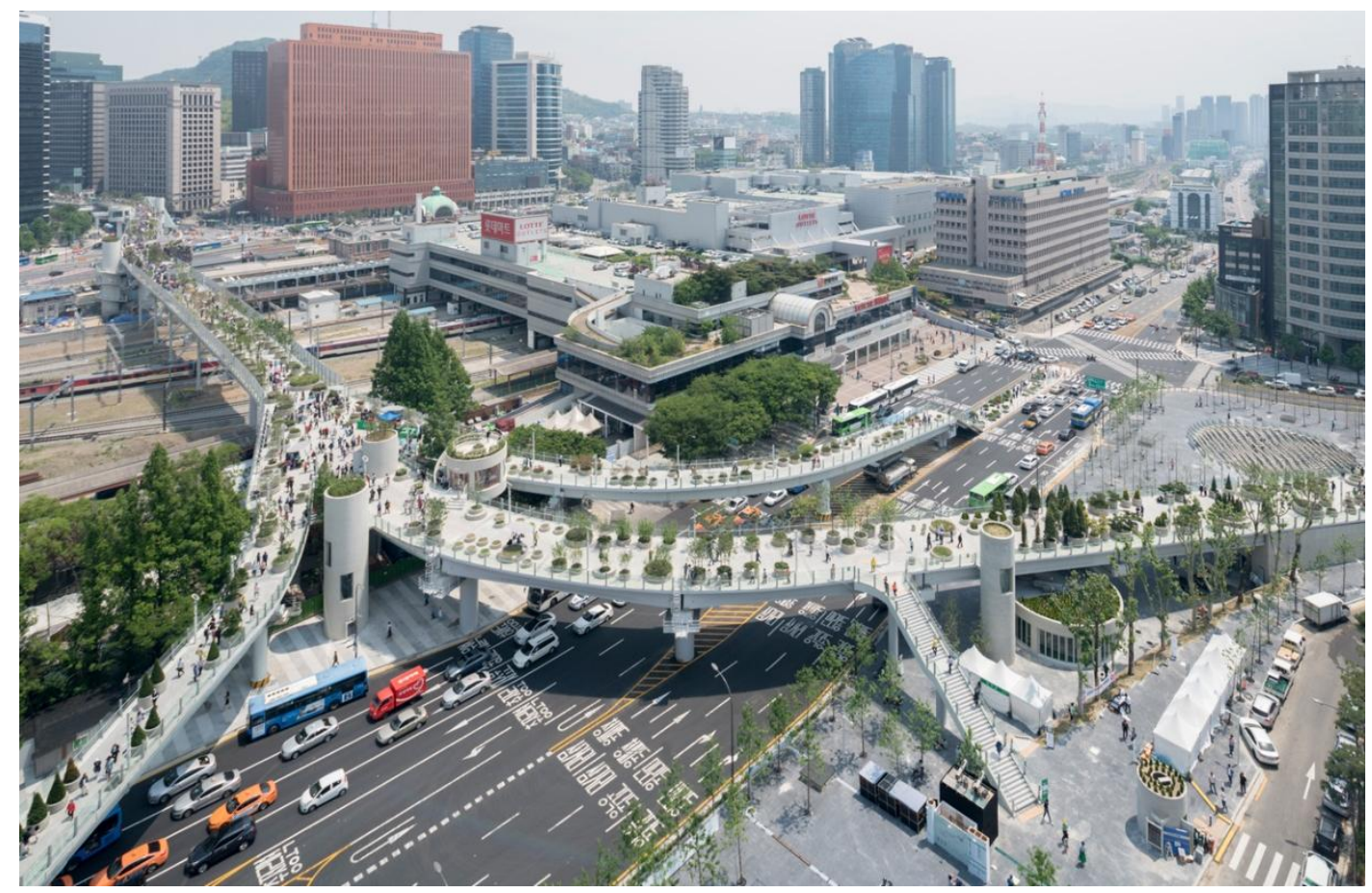

Figure 8. Diverse Plants in Seoullo 7017 Skypark ${ }^{16)}$ 
In community engagement, both projects have similarities while still have their own uniqueness. Since the beginning, both projects involving surrounding communities by giving them opportunities to give inputs to the projects. After completion, both projects also involving community to contribute to maintain it. For example, in Seoullo, the municipal allowed at least 30 homeless people involved in maintain the plants. Similar with Seoullo, Highline also has Friends of High Line community that helping to maintain the park. Moreover, the program that provided in each project also intended to increase community engagement. For example, Seoullo has cultural space, exhibition space, and community development program. In High line, Friends of the High Line hosts more than 450 public programs and activities, aimed at supporting the diverse communities that surround the High Line and facilitating inclusive gatherings for all visitors. From sustainable food vendors and salsa dance parties to kids' activities and historical tours, Friends of the High Line encourages community engagement with the park by curating experiences that highlight the distinctiveness of the space ${ }^{17)}$.

\subsection{Urban Regeneration}

Based on the text in Urban Regeneration book written by Peter Roberts, Urban regeneration defined as comprehensive and integrated vision and action which seeks to resolve urban problems and bring about a lasting improvement in the economic, physical, social, and environmental condition of an area that has been subject to change or offers opportunities for improvement. Roberts also explained about the five inclusive themes as the main objectives of urban regeneration. The aims are:

1. Establish a strong relationship between physical conditions of urban space and social problems,

2. Fulfill the continued needs for the physical replacement of many elements of the urban fabric like housing and industrial areas,

3. Highlight the importance of economic success as a linkage between social growth and urban progress,

4. Make the best possible use of urban land and to avoid unnecessary sprawl in order to ensure optimum beneficial and effective use of land within the urban area and

5. Enable urban policy to be shaped through the collaborative planning process pursued by a multi-agency approach.

Based on that aims that mentioned above, both projects can be highlighted in several aims to perceive it as urban regeneration projects. The first aim is to establish a strong relationship between physical conditions of urban space and social problems. In Seoullo 7017 Skypark project, the city had an issue about disconnected urban space that causing social problems. Citizens are no longer interest to walk and less social interaction due to car-oriented infrastructure. 
The proposal has that aim to solve the problem as a bridge to connecting the patched urban space and increasing social interaction. Similar with Seoullo, High Line also has that aim to give urban space for surrounding community activities that raising social interaction.

The second aim is to fulfill the continued needs for the physical replacement of many elements of urban fabric, in this case, industrial infrastructure. From the aim, it conceived that the abandoned and obsolete industrial infrastructure need to be replaced. But both projects exemplify physical replacement is not cheap and necessary. Instead of that, the alternative is to repurpose the physical structure and fulfill the citizens need by adapting it to recent situation. It can be cheaper, fulfilling the need of citizen, and give more economic benefits.

The third aim is to highlight the impact of economic success as a linkage between social growth and urban progress. Both projects absolutely perform significant economic success. It is shown by the high number of visitors that simultaneously increasing economic activities in surrounding area, such as cafés, restaurants, and hotels. The economic success cannot be separated with linkage between the urban progress and social growth. Urban progress from both projects is surrounding development that increases because of the project. For instance, In High Line, West Chelsea area development accelerated because of the project. In line with that, the number of cafés, restaurants, and hotels around Seoullo also increasing. In linking with social growth, both projects also depend on the role of community who also maintain and revive the projects.

\subsection{Gentrification}

Behind all the beauty and positive impacts that by both projects, they are also do have negative impacts. One of profound negative impact that caused by both projects is gentrification. In Seoullo 7017 Skypark project, residents around the site were left. They moved due to the increasing price of real-estate and also unhealthy strong competition. The previous citizens need to compete with big business players, such as restaurants, hotel, café, and shopping mall. Similar with Seoullo, High Line gentrification turned small residential population around the site into luxurious hotels, residentials, clubs, restaurants, and shopping outlets. The previous citizens who were not able to pay rent replaced by wealthier residents.

This situation causing social inequality for the former citizens. It is opposing the idea of sustainability that embedded in both initial aims of the project. Moreover, gentrification caused homogenous community that erased the previous diversity. To some extent, it is replacing the identity of both contexts. In that condition, citizens have no power to prevent their position, municipality intervention definitely needed to solve the problems. 


\section{CONCLUSION}

Landscape intervention by recycling and creating public space using obsolete infrastructure is one example of urban regeneration. Both projects are good example of how urban regeneration can improve the city. It is shown from the increase of economic activities, social interaction, and environmental improvement. However, from both projects, the intervention still has negative impact.

Both projects bring gentrification issues to surrounding citizens. It creates displacement situation that forcing surrounding citizens to leave their place. To reduce the effect of gentrification caused by the new urban intervention, the local municipality need to prepare strategy.

One strategy that could be used is protecting the local citizens by providing special regulation. It can be applied by limiting the tax, creating minimum rent fee, and spreading business players properties.

In critical review part, the basic concept of High Line is in line with picturesque landscape design principle, by creating images of natural wilderness that is very contrast with surrounding built environment. While Seoullo 7017 Skypark has similar idea with formal landscape principle. It is shown from how the plants arranged in alphabetical order and the pots creating strong borderline between man-made and nature. In political aspect, supports from municipality and the role of visionary mayor are very important for project realization. Besides that, various strategy involvement respecting the context also important to maintain the project. Both projects provide insightful example of approach that can be inspiration for adapting post-industrial infrastructure in specific nowadays context.

\section{REFERENCES}

1) Rees, J., 1966. Industrialization and the Transformation of American Life: a brief introduction. M.E. Sharp, Inc. United State.

2) Loures, Luis. "Post-industrial landscapes as drivers for urban redevelopment: Public versus expert perspectives towards the benefits and barriers of the reuse of postindustrial sites in urban areas." Habitat International 45.p2 (2015) 72-81

3) Doyle, M.W.; Havlick, D.G. Infrastructure and the environment. Annu. Rev. Environ. Resour. 2009, 34, 349-373. [CrossRef]

4) JJL Staff Reporter. (2015). How can cities fight urban decay? Retrieved January 9, 2019, from https://www.jllrealviews.com/trends/how-can-cities-fight-urban-decay/

5) Mehdipour, Armin \& Hoda Rashdi Nia. "Industrialization and City Change; the Concept and Historical Evolution of Urban Regeneration." International Journal of Sciences: Basic and Applied Research 12.1, (2013) 176-181.

6) Lang, Steven \& Julia Rothenberg. "Neoliberal urbanism, public space, and the greening of the growth machine: New YorkCity's High Line park." Environment and Planning A Julia 49.8, (2017): 1743-1761. 
7) Kalmbach Publishing Company, 2019. The History of "Death Avenue" https://www.thehighline.org/blog/2015/10/22/the-history-of-death-avenue-2/

8) Boo, Yeeun \& Young-Sang Kwon. "A Case Study on Sustainable Reuse of Abandoned Infrastructure at Seoul Station Overpass as Urban Park for the Design Strategies in Korea." IOP Conference Series: Earth and Environmental Science 143.1, (2018)

9) Hong, Yan. "Actual condition of Seoullo 7017 overpass regeneration project based on field surveys." Frontiers of Architectural Research 7.3, (2018) 415-423.

10) Seoul Management Team. (2018). Yesterday, today and tomorrow of the Seoul Station Overpass. Retrieved January 11, 2019, from https://seoullo7017.seoul.go.kr/SSF/ENG/H/ARC/010/01010.do

11) Czerniak, Julia, and George Hargreaves. (2008). Large Parks. New York, NY: Princeton Architectural Press.

12) James Corner Field Operations, Diller Scofidio + Renfro. (2015). The High Line: Foreseen, Unforeseen, London: Phaidon

13) おかみさんとさだきち. (2017). Seoullo 7017. Retrieved January 12, 2019, from https://www.tripadvisor.com/Attraction_Review-g294197-d12459260-ReviewsSeoullo_7017-

Seoul.html\#photos;aggregationId=101\&albumid=101\&filter=7\&ff=270662544

14) Iwan Baan, 2008 https://www.thehighline.org/photos-videos/at-a-glance/bestof $/$ gallery $=3854 \&$ media_item $=2008$, accessed 2018

15) Steven Severinghaus https://www.thehighline.org/photos-videos/at-a-glance/bestof/?gallery=3854\&media_item $=2019$

16) MVRDV https://www.mvrdv.com/projects/208/seoullo-7017-skygarden

17) Schmidt, M. (2018). Shaping Seoul Employing Heritage in the Urban Regeneration Projects Seoullo 7017 and Again Sewoon (Master's thesis). Retrieved from https://openaccess.leidenuniv.nl/handle/1887/63787 